\title{
Study on Status of Fish Diseases in Nepal
}

\author{
S. P. Shrestha ${ }^{1 *}$, P. Bajracharya ${ }^{2}$, A. Rayamaijhi ${ }^{3}$ and S. P. Shrestha ${ }^{4}$ \\ ${ }^{1}$ Animal Health Research Division, NARC \\ ${ }^{2}$ Research Assistant, Animal Health Research Division, NARC \\ ${ }^{3}$ Fisheries Research Division, Godawari, Lalitpur, Nepal \\ ${ }^{4}$ Institute of Agriculture and Animal Science T.U, Paklihawa \\ *Corresponding author: swoyamsps@yahoo.com
}

\begin{abstract}
Fisheries play an important role in increasing the Nepalese economy as well as sustaining livelihood of some ethnic groups of our country. With the increased demand of fish, pisciculture have also increased to a great extend. Due to the rise in fish culture, there has been also rise in fish diseases. The study aims to investigate different parasitic, bacterial, fungal diseases in fish and to suggest treatment to control the diseases in four different fish farm of Nepal. A crosssectional qualitative method was used to collect data from four selected fish farm (Kakani, Trishuli, Begnas, Mirmi) of Nepal. Infected fishes were transferred to the lab in oxygen filled plastic bags and further tested for bacterial, fungal and parasitic infection. The result of the study indicates that Epizootic Ulcerative Syndrome was the most common bacterial-fungal disease that had a significant impact on common carp fish especially in Trishuli, Begnas and Mirmi. Coccidiosis caused by Eimeria spp was found to be a growing problem in rainbow trout farming (Kakani, Nuwakot) infecting intestine, liver, gut and skin causing yellow diarrhea and skin lesions. Trichodina was observed number one problematic parasitic in carp culture not only in government farm like Begnas and Mirmi, but also in commercial farms in most of the fishery areas of the country. Fin rot were more commonly reported during winter months affecting common carp, Silver carp, Bighead carp, Fingerling Fish causing fin erosion in them. Ascites in brood fishes (Trishuli) was noticed which may be due to bacterial infection and due to nutritional deficiency. Besides this, white spot in the gills (a protozoan parasitic disease) was perceived and to control it Neodox with Formalin (150ppm) was used and was found to be very effective. This study also identified some fish health management related problems in fish farms of Nepal such as lack of assistance, poor technical knowledge, and lack of suitable diagnostic laboratory and their proper use.
\end{abstract}

Keywords: Fish farming, Fish diseases, Economical loss, Health management, Nepal 


\section{INTRODUCTION}

Nepal lying in between India and China is a small land locked country having three eco-zones, terai in the southern plain, hill in the middle and the mountains in the north. It is rich in term of water resources which makes Nepal a country with great potential in fish farming. In Nepal, 200 fish species are available in which around 190 are indigenous species and remaining are exotic species (Sharma and Sharma, 2008). Commercial fish farming commenced since 1947 with the introduction of pond culture of Indian carps (FAO, 2012). Today, there are many varieties of fishes produced commercially in different parts of the country majority being Rohu, Naini, Bhakur, Carps (Common, silver, grass, and bighead), Tilapia, Puntius, Rainbow trout etc. Among the indigenous fishes, Asla, Katla, Sahar etc. are captured from ponds, lakes and rivers and marketed in the local markets.

Different system of fish culture is practiced and followed in different region of the country. Mostly Indian major carps, Chinese major carp and Cat fish are cultured in earthen ponds, cemented ponds in intensive or semi-intensive way. Besides these, cage culture, pen culture and paddy cum fish culture are also under practice. Government agencies and progressive farmers have initiated cage culture in Phewa, Rupa, Begnas and Kulekhani lakes and dams but preliminary cage culture in lakes and reservoirs with herbivorous carps was initiated with the support of FAO/UNDP and later the International Development Research Center (IDRC) Canada in the 1970s (Karki, 2016). Farmers are also practicing integrated farming system which includes livestock, horticulture along with fisheries. Some ethnic groups (Tharu, Majhis, Kumal, Kewat, Mushar, Boteetc) sustain their livelihood by catching and selling of captured fishes from rivers, ponds and lakes of the country (Budhathoki and Sapkota, 2018).

With increased demands of fish, piscicultures have also increased to great extent. Big commercial fish farmers have practiced fish farming not only in terai region but also it is coming up in the lower hills of the country. The intensive fish culture involves higher rates of stocking and supplementary feeding which has substantially enhanced the incidence of diseases in fishes in our country. Fishes go through wide varieties of diseases of infectious and non infectious etiology in their natural environment. Several literatures are available on fish mortality and morbidity due to bacteria, parasites, fungus, nutritional deficiencies, metabolic disorders and faulty environmental conditions like oxygen deficiency, high or very low water temperature, chemical pollutants, overcrowding, mal-nutrition, algal blooms etc (Mukherjee, 2002). It is estimated that the annual loss in production due to diseases range from 25 to $30 \%$ (Anon, 1996).

Bacterial fish diseases are very common and are one of the most difficult health problems to deal with. Bacterial diseases have been frequently encountered in eggs, fry, fingerlings of fish, causing heavy mortality. These microorganisms are essentially opportunistic pathogens which invade the tissues of a fish host rendered susceptible to infection by stress factors (Sandeep.P, 2016). The bacterial diseases commonly encountered are columnariosis, farunuclosis, tail rot/fin rot, bacterial gill diseases, aeromoniasis, edwardsiellosis, vibriosis, eye disease, pseudomoniasis and enteric red mouth disease (Mishra et al., 2017). Compared to other diseases, the parasitic disease alone causes $8-12 \%$ loss in production (Anon, 1996). Fish parasites multiply rapidly under favourable conditions, there by affecting the health of fishes, often leading to high mortality. Parasites interfere with nutrition of hosts, disrupting the metabolism and secretary 
functions of alimentary canal and damage nervous system (Farhaduzzaman et al, 2010). Parasitic diseases commonly reported in fish culture are Argulidae (Carp lice), Dactylogymus (Gill fluke), ichthyophthiriasis (White spot), trichodiniasis, gyrodactylosis (Skin fluke) and myxosporidiasis (Mishra SS et al., 2014).

Contrasting to bacterial and parasitic diseases, a very few number of fungal species are known to be pathogenic to the fish. Mostly these are present in water and under unfavourable conditions; they attack the fish causing skin lesions. Most fungal infections recorded in carp culture are those caused by species belonging to the oomycete fungi, Saprolegnia, Achlya and Aphanomyces. Diseases caused by these fungi are collectively called "saprolegniasis". The important fungal induced disease in fish culture of high economic importance is Epizootic Ulcerative Syndrome (EUS). It is widely occurred in freshwater aquaculture causing a great loss. It is a severe and economically important disease affecting farmed freshwater fish and listed as a notifiable disease. Other fungal diseases like Branchiomposis (gill rot), ichthyophonosis, aspergillomycoses are also commonly encountered in fish culture (Mishra, 2017).

The study aims to investigate different parasitic, bacterial, fungal diseases in fish and to suggest treatment to control the diseases in four different fish farm (Kakani, Trishuli, Begnas, Mirmi) of Nepal.

\section{MATERIAL AND METHODS}

\section{Selection of Sstudy Area}

The study was conducted in four selected fish farms of Nepal i.e. (Kakani, Trishuli, Begnas and Mirmi) due to abundance of fish resources (fish rearing farmers, societies, fish rearing and availability of hatcheries).

\section{Data Collection and Sampling}

A combination of participatory and qualitative methods was used for data collection. Data were collected from 2072 to 2075 . A traditional survey method of direct interview from the selected fish farmers was followed, using pre-tested questionnaire. After collecting primary data, focus group discussion with farmers and cross-check interviews with key informants were carried out to justify the previously collected data. Fishes were examined for external symptoms and health conditions at the site of the farm. Infected fishes were transferred to the lab in oxygen filled plastic bags.

\section{Test for Parasite}

Intestines of yellow diarrheal syndrome affected rainbow trout were sampled. Collected trout intestine samples were stored in vials of normal saline solution for coprological observation and species identification. The sampled intestines were opened in longitudinal direction and the mucus and fecal material were drawn off. Qualitative fecal examination was performed by McMaster technique with some modification.

\section{Test for Fungi}

The fish samples were disinfected from surface to prevent secondary contamination with airborne spores by dipping fish in $1 \%$ formaldehyde for 1 to $5 \mathrm{~min}$. Then the sample was 
transferred to $70 \%$ alcohol and finally several washings were given in sterilized distilled water. The fungi were isolated from infected organs of fish with sterile needle, inoculated on Potato dextrose agar (PDA). The agar plates were incubated at $28-30^{\circ} \mathrm{C}$ and fungal growth was observed after 5-7days. Slides were prepared by taking material from each colony and stained with Lacto-phenol cotton blue. The slides were observed under microscope and photographed. The fungal identification was done with the help of identification keys and literature.

\section{Test for Bacteria}

Fish samples were collected aseptically. These samples were first enriched then inoculated in respective selective medias then immediately sub-cultured in nutrient agar and incubated at $37^{\circ} \mathrm{C}$ for 24-48 hours and the colony characters were recorded. The colonies obtained on the agar surface were stained with Gram's stain for morphological studies and subjected to conventional biochemical tests for identification of the organisms.

\section{RESULTS}

According to this study, coccidiosis caused by Eimeria spp. was found to be a growing problem in rainbow traut farming (Kakani, Nuwakot) infecting intestine, liver, gut and skin causing yellow diarrhea and skin lesions. Trichodina was observed number one problematic parasitic diseases in carp culture not only in government farm like Begnas and Mirmi, but also in commercial farms in most of the fishery areas of the country. Epizootic ulcerative Syndrome was noticed in Trishuli, Begnas and Mirmi in some breeding fishes which mainly infect the skin causing skin lesions which further expand to form ulcers followed by the development of granulomas on the internal organs and death. It was prevalent mostly during winter months.

Fingerling mortality in Mirmi was mostly due to low oxygen level in water and due to overcrowding. Fin rot was more commonly seen during winter months affecting Common carp, Silver carp, and Bighead carp. Ascites in brood fishes (Trishuli) was noticed which may be due to bacterial infection and due to nutritional deficiency. Besides this, white spot in the gills (a protozoan parasitic disease) was perceived and treated with Neodox with Formalin (150ppm) which was very effective. In slow growth, addition of protein and essential amino-acid in the feed was suggested.

Table 1: Survey lab finding and treatment of different fish diseases.

In slow growth, addition of protein and essential aminoacid in the feed was suggested.

\begin{tabular}{ll}
\hline *Vime-Anticoc (200gm) & *Prolium-K (150gm) \\
Sulfadimidin sodium & Amprolium + Vit K3 \\
Diaveridine HCL & \\
Mendione Na & \\
\hline
\end{tabular}

The other parasitic diseases Argulosis caused by metazoan parasite (Argulus) was found widely in Indian major carps, especially in brood fish. Maximum argulosis problem was found in Mirmi, Syangja. 


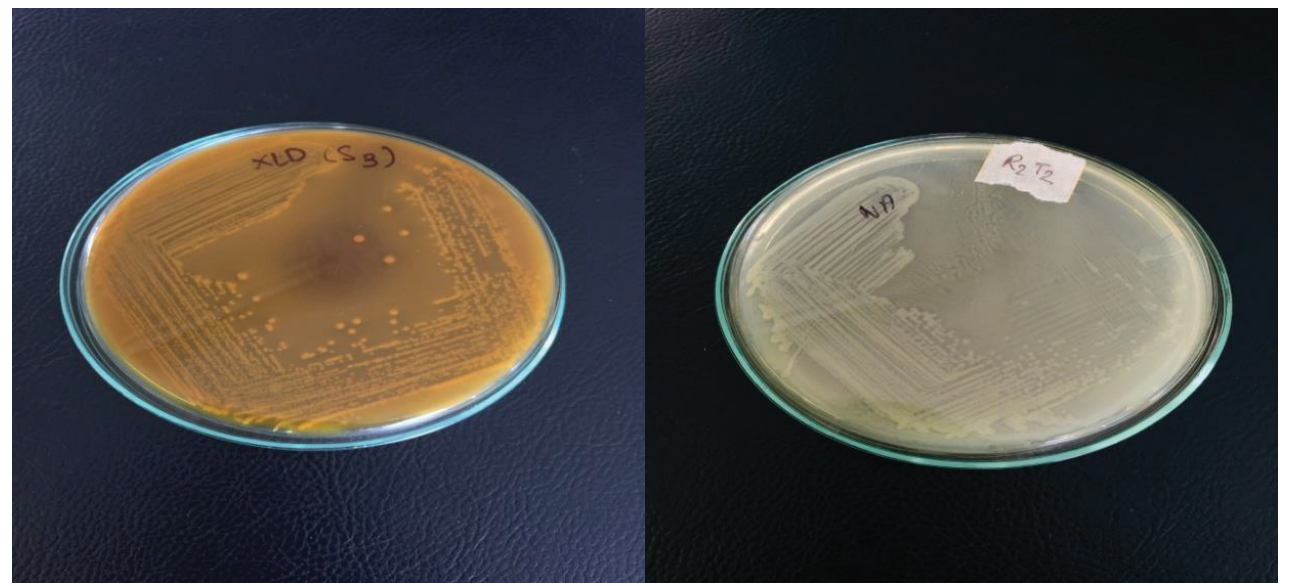

Figure 1: E.coli (Left) and Salmonella (Right) in XLD and Nutrient agar isolated from infected fish sample
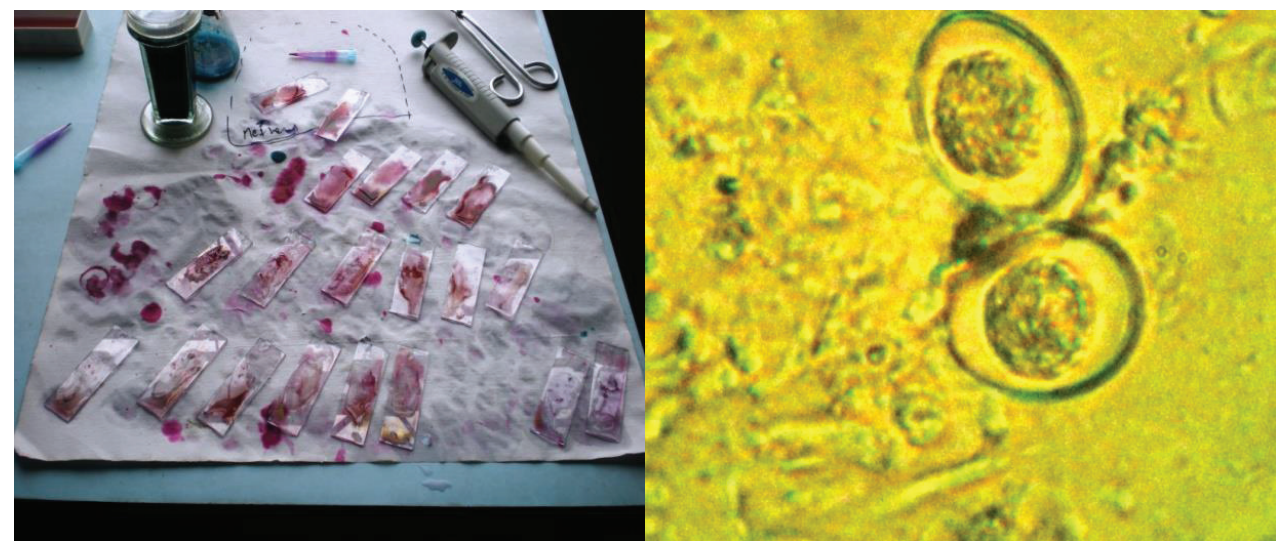

Figure 2: Processing of fecal sample (right) and Eimeria aurati (left) isolated from intestine of rainbow trout viewed under a microscope

Table 2: Feed formulation for trout (breeding stock)

\begin{tabular}{|l|l|}
\hline Ingredients & Percentage (\%) \\
\hline Prawn & 35 \\
\hline Soya cake & 25 \\
\hline Wheat & 15 \\
\hline Rice bran & 13 \\
\hline Mustard cake & 10 \\
\hline Vitamins & 1 \\
\hline Minerals & 1 \\
\hline Total & $100 \%$ \\
\hline
\end{tabular}


Table 3: Other fish diseases that have been reported in Nepal (R. Thakur et al.,)

\begin{tabular}{|l|l|l|l|l|l|}
\hline \multicolumn{5}{|c|}{ Other diseases reported in Nepal } \\
Protozoan & Crustacean & Bacterial & Fungal & Viral & Environmental \\
\hline -Costiasis or Blue & -Lernaeasis & -Tail Rot or & -Saprolegniasis & -Spring & -Gas Bubble \\
Slime Disease & & Fin Rot & - & Viremia & disease or Gas \\
\hline & & -Dropsy & Branchiomycosis & of carp & $\begin{array}{l}\text { Embolism in } \\
\text { hatchings }\end{array}$ \\
\hline $\begin{array}{l}\text { Ichthyopthitiisisor } \\
\text { White spot } \\
\text { disease }\end{array}$ & & & Or Gill rot & & -Asphyxiation \\
& & & -Epizootic & & \\
& & Ulcerative & & \\
& & & Syndrome (EUS) & & \\
& & & & &
\end{tabular}

\section{DISCUSSION}

Persistent occurrence of disease is one of the major curtailments to fish farming in Nepal that may eventually become a limiting factor for its development. The increasing development of aquaculture activities and with intensification of fish culture, has led to increasing number of infectious diseases. The study identified different types of diseases in fish farming in Nepal. A cross-sectional qualitative method was used for data collection. The most commonly reported diseases was Epizootic Ulcerative Syndrome, followed by trichodiniasis, fin rot, gill rot, coccidiosis, white spots, argulosis and dropsy.

The present study showed that Epizootic Ulcerative Syndrome was the most common bacterialfungal disease that had a significant impact on common carp fish especially in Trishuli, Begnas and Mirmi of Nepal. The pathogenic fungus, Aphanomyces invadans and bacteria Aeromonas spp was identified as the causative agent of the disease. In a study conducted by Bagum et al., (2013) revealed that EUS was the most common disease that had a significant impact on major carps fish (C. catla, L. rohita and C. cirhosus) especially in Sylhet (32\%) and Rajshahi (35\%) districts of Bangladesh. Mukherjee (2002) have reported the role of Aeromonas hydrophila in ulcerative disease of fish and identified the biochemical differences among the various strains of these organisms. In most of the case A. hydrophila was found to be isolated although several other bacterial forms (Pseudomonas spp, Vibrio spp and E.coli) were also present as secondary invaders that mainly infect the skin causing skin lesions which further expand to form ulcers followed by the development of granulomas on the internal organs and death. Most of the farmers called it as fish "Ulcers" and can easily recognize the diseases. According to the survey, this EUS usually appeared at the beginning of the winter season and caused severe mortality of the fish. Besides this other fungal infections like saprolegniasis and brachiomycosis (Gill rot) was also observed.

Parasitic infestation has also been the major cause of concern and causing significant setback to freshwater aquaculture in Nepal. According to Anon (1996), it has been estimated that parasitic diseases alone cause $8-12 \%$ loss in production. The fish parasites have the ability to multiply rapidly under poor water quality conditions, affecting fishes and leading to high morbidity. In this study, the fish parasites mostly responsible for the infection were Trichodina spp. and helminth parasite (cestode and nematode). Trichodina spp. attack mostly the gills and skin, 
damaging the host tissue and consuming the resulting dead tissues. Parasites interfere with nutrition of fish, disrupt the metabolism and secretary functions of alimentary canal and often damage the nervous system, thereby reducing growth rate and even causes mortality, as a result causes substantial economic loss in fish culture system.

The other parasitic diseases Argulosis caused by metazoan parasite (Argulus) was found widely in Indian major carps, especially in brood fish. Maximum argulosis problem was found in Mirmi, Syangja. In the study conducted by Kter, Ossain, and Edwanur (2007), highest mortality of carp fingerlings were reported from nurseries infected with protozoan and monogenean parasites. The species Eimeria are considered as significant pathogens of cultured rainbow trout in Kakani, Nuwakot. Eimeria positive rainbow trout showed sluggish behavior, blackish in color, anorexia and yellow diarrheal syndrome. The two anti-coccidial drugs (Vime-Anticoc and Prolium-K) were suggested for the treatment of Eimeria and were found to be effective. A. Rayamaijhi et. al., (2011) suggested a high incidence of eimereriosis in rainbow trout, in semi intensive raceway farming system of Nepal and concluded that Supercox and Coctreat-EP was effective for Eimeria infection.

A wide variety of bacterial pathogens are also responsible for the major losses to the freshwater aquaculture. These microorganisms are essentially opportunistic pathogens which invade the tissues of a fish host rendered susceptible to infection by stress factors. Bacterial diseases like motile Aeromonas septicaemia, Pseudomonas septicaemia, bacterial gill disease, Fin rot and Dropsy were often reported in various fish culture in Nepal. The poor, abnormal water quality acts as a predisposing factor making the cultured fish susceptible to bacterial opportunistic pathogens. According to this study, most of the diseases mainly occurred during winter season during which the water level drops to minimum and the quality becomes very poor. During low temperature, the immune system of fish suppresses making them more susceptible to diseases. (Ahmed, Akter, Nipa, and Hossain, 2009) reported that the immune system of fish suppressed this time due to low temperature and fish become more susceptible to fish disease. A number of chemotherapeutics were reported for controlling fish disease. The two anti-coccidial drugs VimeAnticoc (100 gm in $200 \mathrm{kgs}$ feed), Prolium-K (30 gm in $50 \mathrm{kgs}$ of feed) was suggested for the treatment of Eimeria (Yellow diarrhea) and for the treatment of other diseases Neodox with Formalin $(150 \mathrm{ppm})$ was suggested and was found to be effective. In slow growth, addition of protein and essential amino-acid in the feed was suggested. Faruk et.al., (2012) reported that mostly lime was exceptionally used in treating brood and health management. Lime is very effective in maintaining $\mathrm{pH}$, water color, and turbidity, increase the rate of decomposition and to treat disease fishes. Hence farmers could be suggested to take these preventive measures at the beginning of winter months.Economic losses from diseases are likely to increase as aquaculture expands and intensifies. The estimated economic loss due to fish disease may vary from farm to farm based on the intensity of infection and the management practices adopted by farmers. The lack of awareness about fish diseases and reporting places and diagnostic laboratory, can lower the reporting of the fish diseases by the farmers.

\section{CONCLUSION}

The present study has helped in demonstrating different fish diseases (parasitic, fungal and bacteria) as an alarming problem to the fish farming in Nepal. In this study, the cross-sectional 
qualitative survey was done to determine the status of fish diseases in Nepal. And from this conducted research, it has demonstrated that Epizootic Ulcerative Syndrome was the most common bacterial-fungal diseases followed by Trichodiniasis, Fin rot, Coccidiosis, Argulosis, White spot, Dropsy etc. And among the four places, the fishes in Trishuli, Begnas, Mirmi were highly infected with different parasitic, bacterial and fungal diseases. Chronic mortalities and poor growth caused by disease are generally not recognized. In order to quantify disease losses, farmers should be able to identify disease as the reason for production loss, slow growth or poor harvest. Rural farmers are mostly resource poor with little or no knowledge of health management and have inadequate opportunities to improve management skills. Therefore, it is important to train farmers to carry out field-level diagnosis and assess the likely impacts of diseases.

\section{REFERENCES}

1996, Technical Report (2053/54) Central Fish Hatchery, Balaju, Kathmandu).

A. Rayamajhi and S.P. Shrestha (2011). Isolation of Eimeria aurati from Rainbow Trout in Nepal and Efficacy of different Anticoccidial drugs on Eimeriosis. 30, 59-67.

Ahmed, G. U., Akter, M. N., Nipa, S. A., and Hossain, M. M. (2009). Investigation on health condition of a freshwater eel, Monopterus cuchia from Ailee beel, Mymensingh , Bangladesh. 7 (2), 421-426.

Author, C., Budhathoki, R., and Campus, P. G. (2018). Fish Farming in Nepal: Trend and Consumption Level. 2 (9), 109-115.

Bagum, N., Monir, M. S., Khan, M. H., and International, A. (2013). present status of fish diseases and economic losses due to incidence of disease in rural freshwater aquaculture of bangladesh. 2571.

FAO. (2012). National aquaculture sector overview.

Faruk MAR, Mony SFA, Hasan (2012) Status of biosecurity and health management in fish hatcheries. International Research Journal of Applied Life Sciences. 5 (1), 15-26.

Farhaduzzaman, A.M. M. Manjurul Alam, Mosharrof Hossai, M. Afzal Hussain, M. H., and Rahman. (2010). Prevalence of Parasites in the Indian Major Carp, . 28, 65-68.

Karki, N.P. (2016). Fish farming in Nepal: trends, opportunities and constraints. Nepalese journal of agricultural sciences, pp.201-210.

Kter, M. A. R. A., Ossain, M. D. E. H., and Edwanur, A. N. D. M. R. (2007). Parasitic Diseases of Exotic Carp in Bangladesh. 5 (June), 127-134.

Mishra, S. S. (2017). Present Status of Fish Disease Management in Freshwater Aquaculture in India : State-of-. (October). https://doi.org/10.24966/AAF-5523/100003

Mukherjee, D. S. . (2002). Fish Diseases in India, their causes and control measures. (1603).

Sandeep. P, C. D. . and K. P. . (2016). Present status of Parasitic and Bacterial diseases in Fresh Water Fish Seed Farms in East Godavari District, Andhra Pradesh P.Sandeep 1 *, B.Chamundeswari Devi 2 and K.Phaneendra Kumar 3 1. 117-122.

Sharma, C. M., and Sharma, C. M. (2008). Aquatic Ecosystem Health and Management Freshwater fishes, fisheries, and habitat prospects of Nepal fishes, fisheries, and habitat prospects of Nepal. 4988. https://doi.org/10.1080/14634980802317329

Ss, M., Das, R., Choudhary, P., Debbarma, J., Sn, S., Bs, G. Kumar, A. (n.d.). Present status of Fisheries and Impact of Emerging Diseases of Fish and Shellfish in Indian Aquaculture. $1-22$. 